\title{
Review on vibration control in tall buildings: from the perspective of devices and applications
}

\author{
BG Kavyashree $^{1} \cdot$ Shantharam Patil ${ }^{1}$ (D) Vidya S. Rao ${ }^{2}$
}

Received: 30 April 2020 / Revised: 5 November 2020 / Accepted: 7 November 2020 / Published online: 3 December 2020

(c) The Author(s) 2020

\begin{abstract}
Permanent construction has evolved from the Palaeolithic age to today's skyscrapers. Constructing the structure, which promises occupants safety, has become a concern because of the uncertainties in nature. Therefore in recent years, attention has been given to the development of structural protective devices that could take care of the external loads. Structural control against the wind and earthquake load has been seriously studied where the structure behaves differently for wind and earthquake load has been briefly discussed in this paper. Initially, paper discusses the history of the construction and the passive control system, which was used in structural control, is briefly discussed in this paper. Also, the implementation of active control has been discussed which was introduced later in the structural control for more effective control. But the limitations of the passive and active control system have introduced semi-active control and also the hybrid control strategy. The two mechanisms are put together in the semi-active and hybrid system to obtain all advantages of the algorithm along with overcoming their limitations. The review also briefs about stochastic vibrational control of the structure where randomness is considered in external loads, parameter of the system and also in the external devices which are implemented in the structural control. As construction sector is a complex system, big data analysis, a new field in structural control system is discussed and future scope is also mentioned.
\end{abstract}

Keywords Tall structure $\cdot$ Passive control $\cdot$ Active control $\cdot$ Semi-active control $\cdot$ Hybrid control

\section{Introduction}

One of the most magnificent evolutionary creations on this earth is human beings gifted with the power to manipulate this environment. For the survival of human beings there need the basics such as air, water, food, shelter, sanitation and sleep. All the basic needs are essential but out of these survivors, shelter is a requirement for mitigating vulnerability and community resilience. Initially, during the Paleolithic

Shantharam Patil

patil.s@manipal.edu

BG Kavyashree

kavya.shree@learner.manipal.edu

Vidya S. Rao

rao.vidya@manipal.edu

1 Manipal School of Architecture and Planning, Manipal Academy of Higher Education, Manipal, Karnataka 576104, India

2 Manipal Institute of Technology, Manipal Academy of Higher Education, Manipal, Karnataka 576104, India
Age, people sheltered themselves under the trees during the dry season and opted for the natural caves or cliff sites in the wet season. In the Neolithic Age, the temporary shelter for survival was constructed with the help of grass, wood, brush and usually covered with mud for waterproofing and this type of construction is called "Facal" [1]. The mud was converted into a brick to build the shelter and to overcome the weathering action of the mud, they were sundried or burnt and used. Then comes the construction practice with the mega-giant stones being cut and curved to form the structure. Then human beings started to construct the permanent structures as a place for living, this began taking its shape in Mesopotamia and Egypt. An example of the permanent structures is the Egyptian Pyramids which is a giant structure in history. The increasing population in the community demanded large dwelling arrangements and a need for strong material in the construction industry where the massive masonry structure had an outbreak for slender structure. Then Gustave Eiffel discovers the use of iron in the construction sector which evolved as composite steel material which took the construction industry to a new height. As there was 
Table 1 The present tallest building in the world [8]

\begin{tabular}{lllll}
\hline Building name & Country & Completed year & Height (m) & No. of stories \\
\hline Burj Khalifa & Dubai, UAE & 2010 & 828 & 163 \\
Shanghai Tower & Shanghai, China & 2015 & 632 & 128 \\
$\begin{array}{l}\text { Makkah Royal Clock } \\
\quad \text { Tower Hotel }\end{array}$ & Mecca, Saudi Arabia & 2012 & 601 & 120 \\
$\quad$ One World Trade Center & New York, U.S. & 2014 & 541 & 94 \\
$\begin{array}{l}\text { Taipei 101 } \\
\text { Shanghai World Financial }\end{array}$ & Taipei, China & 2004 & 508 & 101 \\
$\quad$ Center & Shanghai, China & 2008 & 492 & 101 \\
$\begin{array}{l}\text { International Commerce } \\
\quad \text { Center }\end{array}$ & Hong Kong, China & 2010 & 484 & 108 \\
$\begin{array}{l}\text { Petronas Tower 1 and } \\
\text { Petronas Tower 2 }\end{array}$ & Kuala Lumpur, Malaysia & 1998 & 452 & 88 \\
\hline
\end{tabular}

a drastic increase in the population, the construction of permanent structures became a primary essence of civilization. In this journey, the introduction of skyscrapers took place in Chicago in 1885 named Home Insurance Building with height of 138 feet. Chicago was the first place to invent the skyscraper which used steel-frame with curtain walls instead of load-bearing walls in 1884 with the completion of the Home Insurance Building. After construction of Home Insurance Building within five years the masonry structures and steel frame structures were constructed with the increasing height; disappearing the Home Insurance Building in the top ten building list of the 1890s. In the 20th century, development took over the New-York as the capital for a high-rise building. Initially, steel was being used for the construction but concrete took over steel later because of the lesser cost of construction, better resistance to fire and better damping capacity. The reinforced concrete building first come into existence in the USA named Ingalls Building in Cincinnati. Concrete was not been used in the high-rise building because of the weak tensile capacity and under-developed calculation for reinforcement [2]. But when the tubular structure was developed by Fazlur Rahman Khan the concrete was being used for the primary structure. At that time the tallest building record was set by buildings like John Hancock Center, Willis Tower and World Trade Center in the US. Then the evolution of high rise buildings with the structural elements like outriggers and buttress core has given rise to skyscrapers like Taipei 101, Petronas tower and present world's tallest building Burj Khalifa [3-5]. In the tall building, the problem always is of the elevators, to reach the top floor and its disadvantage of space occupancy. Fazlur Khan invented sky lobby, in the floors, where the elevators would directly reach the sky lobby from the bottom. In tall buildings, vertical transportation was an issue and even today in design considered it poses the problem of utilization of floor space; the satisfactory travel time and a brief explanation of elevators installed in world tall buildings are stated in the article [6]. From the beginning, the skyscrapers are the dream of the architecture, symbol of economic wealth and power. Even today there is a contest for the development of the tall building continues, with the discovery of new materials, construction systems, and efficient elevators. Table 1 describes building name, country, completed year, height and no. of stories of present tallest skyscrapers in the world as referred to the articles [7, 8].

These skyscrapers are vulnerable to lateral forces like wind and earthquakes. Therefore structural control strategy for vibration mitigation is a must for the structural design of skyscrapers. The fundamental principle of vibration control is to introduce vibrations in the parameter of the dynamic system (linear or non-linear) such that the system properties changes in the desired way so that the system is stable for all transient motions and external disturbance [9, 10]. Structure behaves differently for the external disturbance like wind, which acts like force type loading and for earthquake, which acts like displacement type loading depending on the frequency of multi-hazard excitation. Many studies have compared the wind and earthquake excitation for the same building showing that the earthquake with high acceleration for a short time instant will excite higher modes, cause small drift. On the same time wind load with less acceleration is present for a long period will cause larger drift and comfort issue within the occupants [11, 12]. In the structural control, damping and stiffness play an important parameter in the structural response as presented in the article [13, 14]. Initially, the classical pole placement techniques were introduced in the control systems. This pole placement technique has been employed for the structural vibration control by authors in paper [15] by modifying the mathematical background of the algorithm as for the building systems are fixed systems. Mainly the control algorithms and protective systems are of different types and classification as presented in the article [16]. There are many vibration protective systems like passive systems, active systems, semi-active systems and hybrid protective systems. A brief review of the structural 
protective systems is stated in Sects. 2, 3, 4, 5, 6, 7. From the literature survey done, there are studies on tall building analysis with stochastic optimal control, some of the literature on quantification of control effectiveness of stochastic control by taking uncertainty as the inherent randomness in the dynamical behavior of the dampers, desired random excitations passed through the suitable filters for earthquake disturbances etc. are elucidated in the further section, but there is a need to concentrate in improving structural health monitoring. The tall building vibration control needs the ability to process large amounts of data, thus the structural control of tall building need a study on big data analysis techniques in its control schemes. Big data is still an upcoming practice and relatively new methodology of structural health monitoring, it has enormous uncapped potential in the construction sector. Some of the related literature on big data in construction sectors are elaborated in this paper.

\section{Passive control}

The structural control system against the lateral load was necessary to keep the tall building comfortable to the occupants and undisturbed to the external uncertainties. First among the control system introduced are a passive control system used in the structures and connecting bridges. In a passive protective system, the vibration of the structure due to the lateral loads like wind and earthquakes will be mitigated by dissipating the external load transferred into the structure into other sources of energy or by segregating the structure from the external load by some structural modification to reduce the vibration. In this system it does not use an external power source in controlling vibration, therefore there is no threat about the breakdown of the passive system during any seismic event. Thus this system is easier in installation, maintenance and economic from all the prospects in mitigating the structural response. But it has some limitations as it does not use external power but use the motion of the system itself for its technical process of working and its control forces cannot be changed as per the requirement during the seismic event means it cannot adapt to the situation. But the isolators and energy dissipaters enhance the structural control during the seismic event by dissipating the seismic energy using the structural vibration to convert kinetic energy to heat or by transferring energy among vibrating modes proving its effectiveness in the reduction of the effect of lateral load on the structure [17]. By using the passive protection system the recent development of optimum control of the structural response is found in the article [18]. A novel passive shock absorber called velocity and displacement dependent damper is introduced in the article [19], which is compared for semiactive control damper and the results showed that velocity and displacement dependent damper could perform as good
Table 2 Classification of the passive protective system

\begin{tabular}{|c|c|c|}
\hline \multirow[t]{6}{*}{$\begin{array}{l}\text { Isolators- base } \\
\text { isolation systems }\end{array}$} & $\begin{array}{c}\text { Elastomeric } \\
\text { isolators }\end{array}$ & $\begin{array}{l}\text { Natural rubber } \\
\text { bearings }\end{array}$ \\
\hline & & $\begin{array}{l}\text { Low-damping } \\
\text { rubber bearings }\end{array}$ \\
\hline & & Lead-plug bearings \\
\hline & & $\begin{array}{l}\text { High-damping } \\
\text { rubber bearings }\end{array}$ \\
\hline & Sliding isolators & $\begin{array}{l}\text { Resilient friction } \\
\text { system }\end{array}$ \\
\hline & & $\begin{array}{l}\text { Friction pendulum } \\
\text { system }\end{array}$ \\
\hline \multirow[t]{6}{*}{ Energy dissipation } & Hysteretic device & $\begin{array}{l}\text { Metallic yield } \\
\text { dampers }\end{array}$ \\
\hline & & Friction dampers \\
\hline & Visco-elastic device & $\begin{array}{l}\text { Viscoelastic solid } \\
\text { dampers }\end{array}$ \\
\hline & & $\begin{array}{l}\text { Fluid viscous } \\
\text { dampers }\end{array}$ \\
\hline & Re-centering device & $\begin{array}{l}\text { Pressurized fluid } \\
\text { dampers }\end{array}$ \\
\hline & & $\begin{array}{l}\text { Preloaded } \\
\text { spring-friction } \\
\text { dampers }\end{array}$ \\
\hline \multirow[t]{3}{*}{ Energy transfer } & $\begin{array}{c}\text { Tuned mass } \\
\text { dampers }\end{array}$ & \\
\hline & $\begin{array}{l}\text { Tuned liquid } \\
\text { dampers }\end{array}$ & Sloshing dampers \\
\hline & & Column dampers \\
\hline
\end{tabular}

as a semi-active damper. In the article [20] authors have classified passive protective systems as main types and subtypes as stated in Table 2.

\subsection{Seismic base isolators}

The base isolation technique was invented due to the sheer necessity of making structures earthquake resistant. From its first conceptual idea in 1909 B. C. by a doctor named Calantarients, where it was suggested to use the talc layer between substructure and superstructure, the concept has now fairly mature. Later many varieties of isolators have been invented and have been successfully implemented in many countries. The fundamental concept of an isolator is to offset the harmful effects of an earthquake by isolating the superstructure from the substructure. The main principle of base isolation devices is to introduce a layer between the foundation and superstructure which is stiff in a vertical direction and very flexible in a horizontal direction [21]. As the isolators are very flexible in a horizontal direction when compared to the superstructure it will introduce a new mode of vibration to the superstructure, which will elongate the fundamental period of the superstructure and this period will not match with 


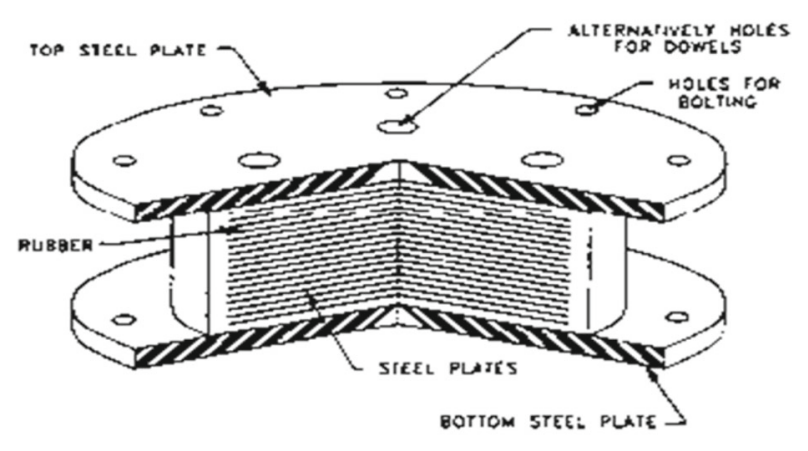

Fig. 1 Elastomeric bearing

the period of input. The main aim of base isolation is (i) to change the fundamental frequency of the superstructure from the dominant frequencies of input (ii) to reduce the displacement by increasing the adequate amount of damping material in isolators such as lead.

\subsubsection{Elastomeric isolators}

Elastomeric isolation is a combination of thin vulcanized natural rubber and steel plates with the holes for the dowel. In elastomeric isolation, there are several types of bearing like natural rubber bearings, low-damping rubber bearings, lead-plug bearings and high-damping rubber bearings. Elastomeric systems make use of natural rubber or synthetic rubber as the principal component. Base isolation of Pestalozzi school in Skopje, in 1969 using large rubber blocks is one of the earliest and well-known examples of usage of elastomeric systems. Figure 1 shows elastomeric bearing.

These blocks are relatively undamped, compress by $25 \%$ vertically and with a significant horizontal bulging, which indicates a lack of vertical stiffness. Due to this property, some amount of horizontal acceleration is converted as vertical acceleration which is one of the major drawbacks of these blocks. Due to this drawback, the usage of such blocks was discontinued further. To address the issue of lack of vertical stiffness, such blocks were reinforced with steel plates and are called as laminated rubber bearings. These bearings are capable of providing vertical stiffness and also address the issue of horizontal bulging. Several varieties of laminated rubber bearings were developed and used in many structures. The following are the various classification of laminated rubber bearings that are elucidated further.

Low damping rubber bearing is made up of natural or synthetic rubber with two thick steel plates at the ends and thin steel sheets in between. These bearings show linear behavior when subjected to shear force. The effect of creep is not seen in these bearings and the manufacturing process of these dampers is also quite simple. These bearings provide negligible damping. But, some amount of damping is always desirable and hence, these bearings have to be used

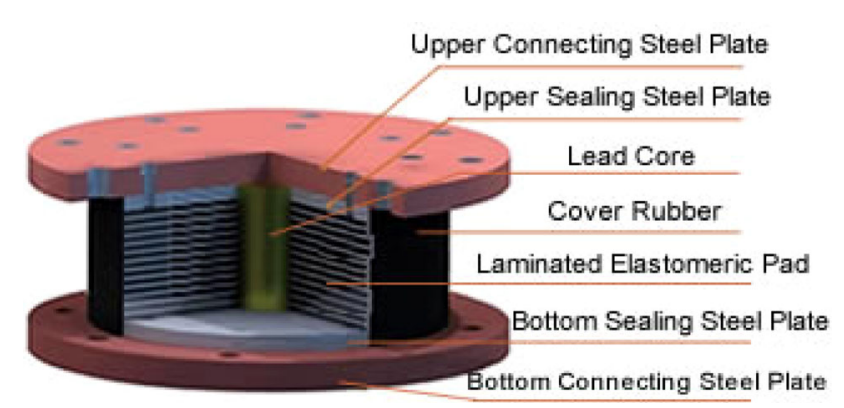

Fig. 2 Lead rubber bearing components

along with supplemental dampers. Connecting a damper to an isolator is complex work and hence, this is one of the disadvantages of low damping bearings.

Due to the advancement in rubber technology, additional required damping can be provided by adding resins, oils, or some filler to the rubber to produce high damping rubber bearing. Thus the need for supplemental dampers can be eliminated. Due to the material used, the bearing behaves nonlinearly at low shear strains and provides high damping and stiffness. At moderate levels of shear strain, the bearing behaves linearly. At a higher shear strain both stiffness and damping of the bearing increases. Thus, these bearings can be designed to behave very stiffly for a less magnitude input such as wind load, fairly stiff during design earthquake and very stiff during an earthquake that exceeds design level earthquake. The manufacturing process of these bearings is similar to low damping bearings and cost-effective as well.

To enhance the hysteretic damping, a lead core is inserted at the center of laminated rubber bearing. The additional hysteretic damping is provided due to the plastic deformation of lead. Lead Rubber Bearings (LRB) behaves nonlinearly and the hysteretic behavior of LRB can be idealized as a bilinear curve. Thus, elastomeric present in the bearing provides isolation property whereas, the lead core provides damping property to the bearing. One of the disadvantages of LRB mentioned in paper [22], during strong near field earthquakes, bearings undergo hardening which significantly increases the displacement. Figure 2 shows lead rubber bearing components.

\subsubsection{Sliding isolators}

During earthquakes in Bihar and Dubai, in the year 1934, it was observed that many masonry buildings did not collapse, because they simply slid on their foundation during an earthquake. Whereas, buildings which were connected completely to the foundation collapsed. This observation led researchers to develop alternative systems for isolating masonry buildings. In the article [23] authors proposed a pure sliding concept to avoid the harmful effects of the earthquake on masonry buildings. Later, in the article [24] authors pro- 
posed natural rubber bearings along with a skid system and tested its effectiveness for a scaled model of the building. In sliding based systems, energy dissipation usually takes place due to friction between contact surfaces. The systems, which were developed based on the sliding concept are further elucidated,

Pure Friction (P-F) systems are the simplest of all sliding isolation systems. Here, the superstructure is isolated by providing rollers [25], Teflon sliding bearings [26] a layer of black polyethylene sheet [27], or simply a layer of sand [28], etc. between superstructure and foundation, which provide resistance through pure friction [29]. The force developed at the base in this system is due to mass and friction coefficient. Robust optimization of passive friction damper is introduced in the article [30], which considers the uncertainties in structure, as well as load properties using genetic algorithm, were studied for a structure in Colombia excited for an earthquake. The disadvantage of this system is that, after a seismic event, the system will not move back to its original position. That is, re-centering of the system does not take place and hence, an additional system may be required to bring the system to the original position and whenever a frictional surface is provided, the surface is sensitive to pressure, relative velocity, etc. This induces nonlinearity and hence a nonlinear dynamic analysis may be necessary, which is a tedious process.

The main issues usually associated with the P-F system are excessive displacement of the structure during an earthquake event and residual displacement at the end of the earthquake. To overcome these drawbacks, the Friction Pendulum System (FPS) was proposed in the article [31]; this system makes use of its geometry and gravity to achieve seismic isolation objectives. Here, the isolator consists of an articulated slider that moves on a stainless steel spherical surface. The slider is coated with stainless steel and is located in a cavity made in a spherical stainless steel plate. A portion of the slider in contact with a spherical surface is coated with a composite material that has low friction. Whenever the slider moves it lifts the mass and provides the necessary restoring force. Figure 3 shows a cross-section of friction pendulum bearing. The friction between the slider and surface provides necessary damping. In FPS, residual displacement is significantly reduced due to the geometry of the isolator itself. Due to the spherical geometry, the time of the isolator remains the same and thus, when earthquake frequency is closer to the isolator frequency, the problem of resonance might arise. Further, several research works have also been carried out on a multistage friction pendulum system. Depending on the number of pendulum mechanisms these are called double pendulum bearings [32] and triple pendulum bearings [33].

To address the resonance issue of FPS, various modified systems were developed based on the modified geometry of the sliding surface. One such system was proposed by [34] is known as a Variable Frequency Pendulum Isolator (VFPI)

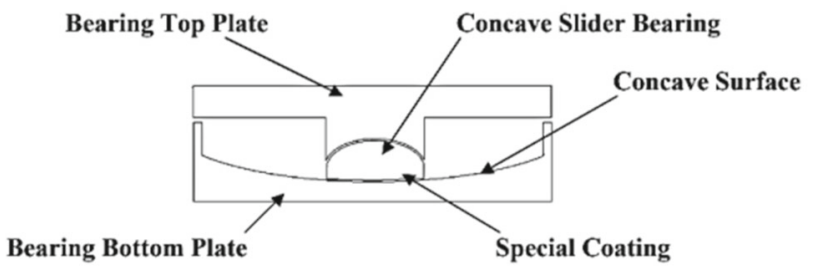

Fig. 3 Cross-section of friction pendulum bearing

system with an elliptical surface, whose frequency varies with the sliding displacement. Since the frequency of the VFPI system is not constant, the system does not show any resonance. A similar isolator was developed by [35] called as Variable Curvature Friction Pendulum System (VCFPS). The system makes use of a concave surface, which is derived by subtracting a function from the equation of FPS. In paper [36], the authors proposed a Conical Friction Pendulum Isolator (CFPI), with a modified geometry of FPS. Within some threshold, the surface is similar to FPS but beyond that, it becomes tangential to the spherical surface of FPS. Further, [37] proposed a sliding surface governed by a polynomial function, known as polynomial friction pendulum isolator (PFPI). Another approach considered by authors in the article [38] is to avoid resonance in FPS is to vary the coefficient of friction along a curved surface. Such a system is known as a Variable Friction Pendulum System (VFPS). Thus, either by changing the geometry or by varying the coefficient of friction along the surface, isolators can be made effective. Based on this, in the article [39] authors proposed an isolator, whose radius of curvature and friction coefficient varies along the surface, known as variable frequency and Variable Friction Pendulum Isolator (VFPI). Here, the surface geometry varies exponentially and the friction coefficient varies linearly along the surface. When compared to FPS which makes use of spherical geometry, all other systems which are developed based varying the geometry of FPS have flatter surface and thus have a tendency for increased displacement. To avoid such large displacements in the article [40, 41] authors proposed a combination of Variable Curvature Pendulum Isolator (VCPI) along with Viscous Fluid Damper (VFD).

\subsection{Energy dissipation}

Energy dissipation devices are relatively small compared to other building components that are installed between the main structures and bracing system. These devices are used as indirect dampers in the structure to absorb or divert some part of input energy or convert kinetic energy to heat so that energy transfer to structure reduces which in turn minimizes the damage occurs in the structure. Passive energy dissipation systems consist variety of devices and materials to alter damping; it could be used for earthquake response reduc- 
tion. The energy dissipaters are classified as hysteretic device, visco-elastic device and re-centering device as stated in the article $[42,43]$. The viscous damper is one of the most used passive dampers and many research have been carried by using this damper for a different type of structure, which has been presented in the article [44-48]. The cost constraint of using a large number of the viscous damper is also an issue, so a study has been conducted in [49] to optimize the viscous damper by three control algorithm used considering the damping ratio for a mode of structural excited for the El-Centro earthquake. Hysteretic devices are metallic yield dampers and friction dampers. Visco-elastic devices are visco-elastic solid dampers presented in the article [50] and fluid viscous dampers. The re-centering device is pressurized fluid and preloaded spring-friction damper. In the metallic damper's dissipation of input, energy depends on the metal used in the device to sustain as many cycles of stable hysteresis behavior. A study has been conducted by using a bar fuse damper which is developed from the common steel section as energy dissipater by article [51], which dissipates the energy with the replaceable bars as sacrificial elements through the flexural and tensile mechanism. This fuse damper was evaluated with a component of steel pipe called pipe fuse damper [52], numerically and experimentally showed stable hysteretic behavior and appropriate displacement reversal as energy dissipation and after failure the replacement of pipe component is easy. Many types of devices have been used as energy dissipaters that use flexure, shear, or longitudinal deformation modes into the plastic range.

\subsection{Energy transfer devices}

The two types of energy transfer devices are Tuned Mass Damper (TMD) and Tuned Liquid Damper (TLD). The TMD was first used for ships to reduce its rolling motion and vibration of the ship hull [53]. In the article [54] theory for TMD is explained and in the article $[55,56]$ the optimum tuning and damping parameter for the efficient performance of TMD is elucidated. TMD consists of huge mass, damping device and properly tuned spring, providing a frequency-dependent hysteresis that increases damping in the primary structure. The huge mass spring damper will be attached to the main structure, almost at the top of the building, to counteract the motion of the ground by mitigating the structural dynamic response [57]. When the lateral load hits the structure, it starts to vibrate and the kinetic energy produced by the structure will be absorbed by the damping device of TMD and vibration will be transferred from structure to TMD, therefore it experiences large displacement is presented in an article [58]. Adaptive-passive variable mass TMD is proposed in the article [59,60], which can vary its mass with the help of sensors, microcontrollers and actuators to retune itself to control structure which can overcome the limitations of normal
TMD. TLD and Tuned Liquid Column Dampers (TLCD) work with a similar principle as TMD instead of using a spring-mass damper it uses the movement of the liquid to absorb the lateral load and stabilize the structure indirectly by adding damping to the structure. This device absorbs the energy from the structure through sloshing motion and dissipates it by wave breaking effect and viscous effect of fluid. TLDs are more beneficial than TMDs: they have less cost of maintenance, simultaneous reduction of motion in two directions can be done, requires less stroke length and no activation mechanism as stated in the article [61]. TLCD work-alike TMDs; they introduce indirect damping to increase structural behavior by generates high-flow turbulence by the passage of a liquid through orifices.

There are some of the disadvantages of the passive damping system, such as size issue; it is a huge device, very heavy and requires a lot of space for its occupancy. Moreover, it works on the tuned frequency for whichever frequency they are tuned at, i.e. structure will have several modes with several frequencies and a single device can be tuned to a single frequency and many devices need to be attached for different frequency which is practically not possible. As the years emerge the structure gradually changes its natural period where these devices will become less effective in the reduction of vibration of the structure.

\section{Active control}

Active control protective system consumes a large amount of external energy from kilowatts to megawatts to apply force to the structure either to add or dissipate energy. There are many active control systems such as Active Mass Damper (AMD) systems, active tendon systems, active brace systems, diagonal braces and pulse generation systems [62]. The first active control system used in the real application was for Kyobashi Seiwa, an 11story building in 1989, in Japan [63], this was installed by Kajima Corporation. Analysis of the building showed different mode shapes of the building with different frequencies and different types of motion, so two AMDs were used to control the transverse and torsional motion [63]. An instantaneous optimal algorithm is an active control algorithm used for three and five-story structures for vibration reduction by authors in paper [64], Fig. 4 shows the reduction in the roof displacement for three story building excited for earthquake load.

There is a control algorithm that varies the stiffness called variable stiffness damper that takes care of damping and reduces the vibration as many studies have used this device to mitigate the structural vibration [65-69]. Linear optimal control, pole assignment technique, independent modal space control, instantaneous optimal control, bounded state control, non-linear control, generalized feed-back control, sliding 


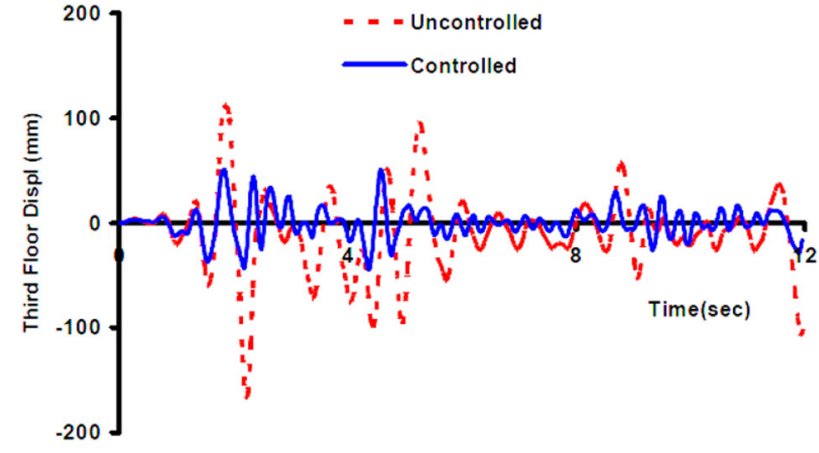

Fig. 4 Roof displacement of a three story building excited for earthquake load

mode control, time-delay compensation, active control using neural network and fuzzy logic are some of the active control algorithms which control the structure and it is elaborated in the article [70].

\subsection{Active mass damper systems}

To overcome the limitation of the passive protection system used for structural control which works more on dominant first mode than other modes and certain frequency of the structure. Instead of a tuned mass damper, an active mass damper was proposed which works on a wide range of frequencies. In this damper, the actuators are installed in between the structure and auxiliary system and the control algorithm with the actuator adjusts the motion of the auxiliary system, therefore the control system and actuator needed is of small size while comparing to the other active control system. In an active control system other than AMD the actuator used to control the motion will act on the structure directly as the size of the structure is large, a huge actuator system is required. But there is a drawback of this system that it works well at the fundamental frequency and at high frequency its efficiency reduces [71].

\subsection{Active brace systems}

The bracing system can be introduced with the actuators (i.e. active control device), where it can be integrated by diagonal bracing, $\mathrm{K}$-bracing, and X-bracing. The hydraulic actuator is placed between the bracing and the adjacent floor along with the servo-valve, a hydraulic power supply, a servo valve controller which is control by a defined control algorithm from the computer. The predefined control algorithm in the computer will produce the required control signal depending on the sensor measurements and the servo valve will reduce the response depending on the control signal.

\subsection{Pulse generation systems}

In this system, the hydraulic actuator is not used, instead the pulse generator is used which works on the pneumatic mechanism that uses compressed air that uses high-pressure fluids. This pulse generator works when there is a large velocity in its vicinity, it produces the force required according to the velocity of the structure. There are some advantages of this device like the use of compressed gas but there are some disadvantages also, the device is not powerful to control the building and the device is highly non-linear.

The advantage of the active control system is that it will tune to the required frequency in the real-time application than seen in a passive control device. However, some disadvantages have made the limited application of an active control system in the civil engineering industries. The main disadvantage is the usage of an external power source for the production of the control force. The cost and huge supply of power sources are required to output the large control force by the actuator to reduce the response of the building. There is another disadvantage that during any uncertainty like an earthquake if power supplies disconnect with the building the active control is likely to be inactive during the peak requirement of control force which makes it a depraved device.

\section{Semi-active control}

Semi-active control devices have proved to be promising in structural control because it combines the merit of reliability in the passive system and adaptability in active system. This system uses very little energy to change the mechanical property of the device and to produce the forces opposed to the structural motion which is produced by using the motion of the structure itself. The use of very small energy which can be fed by battery will not destabilize the system but in active control because of the use of a large amount of energy destabilization takes place during an earthquake. These semi-active devices use less energy which can use the power from a battery and can also provide adaptive control [72]. They cannot add or remove energy to the structure but can change the structural parameter like spring stiffness or damping coefficient. The semi-active control device includes sensors, control computers, control actuators, and passive control devices as presented in the article [73, 74]. There are many control algorithm considered in regulating the semi-active device like pole placement algorithm, clipped optimal control algorithm, Lyapunov controller, decentralized bang-bang controller, modulated homogeneous friction controller, passive-off controller, passive-on controller, skyhook control controller, linear matrix inequality controller, modal space controller, linear-quadratic regulator controller, linear-quadratic-Gaussian controller etc. one of the studies 


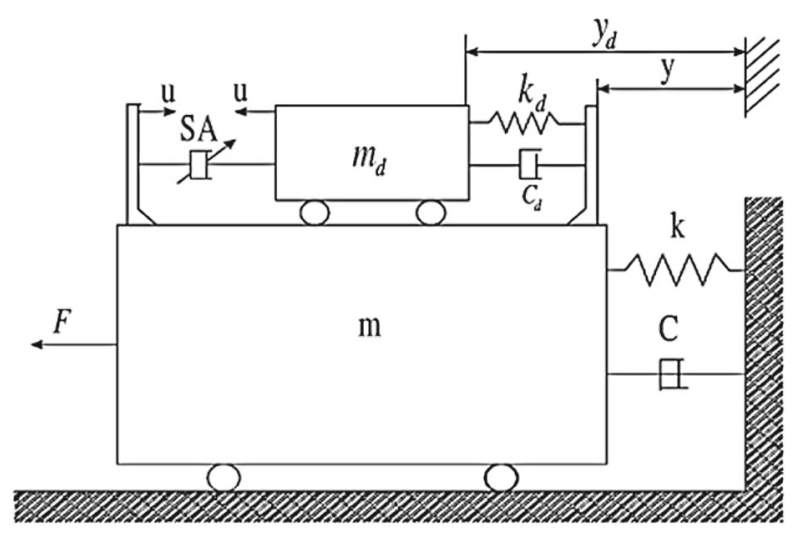

Fig. 5 Mechanical diagram of the semi-active tuned mass damper

has adopted energy-based probabilistic modified independent modal space control to improve the modal space control method by employing the Lyapunov function to improve the performance of the control system in regulating the semiactive controller [75].

\subsection{Semi-active tuned mass dampers}

Tuned mass damper in passive control and active tuned mass damper in active control has a huge mass, that requires large space and a large power supply to trigger the motion of the mass device. Figure 5 shows a semi-active tuned mass damper, its features are its mass, damping and stiffness named as $\mathrm{kd}, \mathrm{md}$, cd; the main structural mass, damping and stiffness are named as $\mathrm{m}, \mathrm{c}, \mathrm{k}$. The control force is represented as $\mathrm{u}$ and $\mathrm{SA}$ as an actuator.

In semi-active tuned mass damper the mass attached is small compared to the previously tuned mass damper explained, which consist of mass, damping and stiffness device and an actuator which continuously produces the control force with the small amount of external power to adjust the damping of TMD as presented in articles [76-78].

\subsection{Semi-active tuned liquid dampers}

Semi-active tuned liquid damper works on the principle of TLD and TLCD. In semi-active tuned liquid damper they used rotatable baffle walls in the tank with sloshing action. An actuator has been used in controlling the rotation of the baffle wall by using the predefined control algorithm. The frequency of the system is decided by the length of the tank, by rotating the baffles to the desired inclination its behavior can be tuned. Inside the tank, the baffles are placed in the horizontal and vertical position, when they are in the horizontal direction the full length of the tank is available and when they are in the vertical direction the tank is divided into the number of small size tanks shown in Fig. 6. Thus the actua-

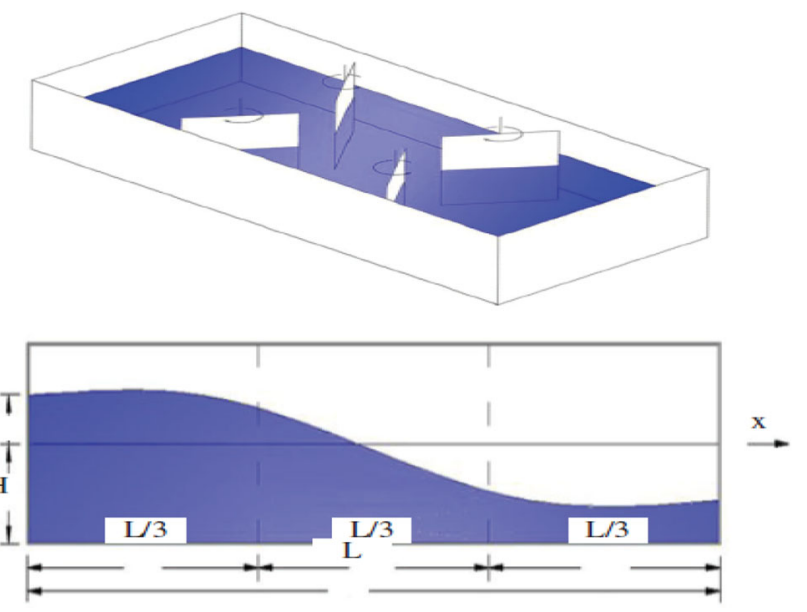

Fig. 6 Semi-active tuned liquid damper with some standing rotatable baffles

tor only needs to rotate the lightweight baffles to change the damper's responses. A novel concept of semi-active tuned liquid column damper which changes its natural frequency and damping ratio adapting to the changes in loading and the structural condition is presented in [79].

\subsection{Semi-active friction dampers}

These dampers mostly use surface friction to dissipate vibratory energy to mitigate structural response. Piezoelectric Translator (PZT) materials when exposed to the electric field with the constrained motion will produce stress. Figure 7 shows Piezoelectric Friction Damper (PFD). This device contains four PZT stack actuators, four preloading units and a steel box for housing other components. When there is motion between bottom plates and isolated plates friction is produce which is the dissipation of energy. The electric field controls the PZT actuator, in turn, tunes the friction forces within the damper, allowing its efficiency to be altered in real-time at a low cost $[80,81]$. Because of the alteration in real-time, this can be used for a weak and a strong earthquake with the development in force generation capacity [82, 83]. An integrated scheme involving semi-active vibration control was introduced in the article [84] with the addition of stiffness which modifies system parameters and based on the updated system parameter the structural control is done by feedback control with Kalman filter.

A study was conducted which used a semi-active friction damper with five control strategy as friction force as a resistance when the system is deviating from its equilibrium position, maximizes the energy removal in each harmonic oscillation cycle by calculating the optimal normal force based on the last displacement peak, the first strategy with the homogenous modulation of the friction force, predict the system's movement based on its velocity, acceleration and 

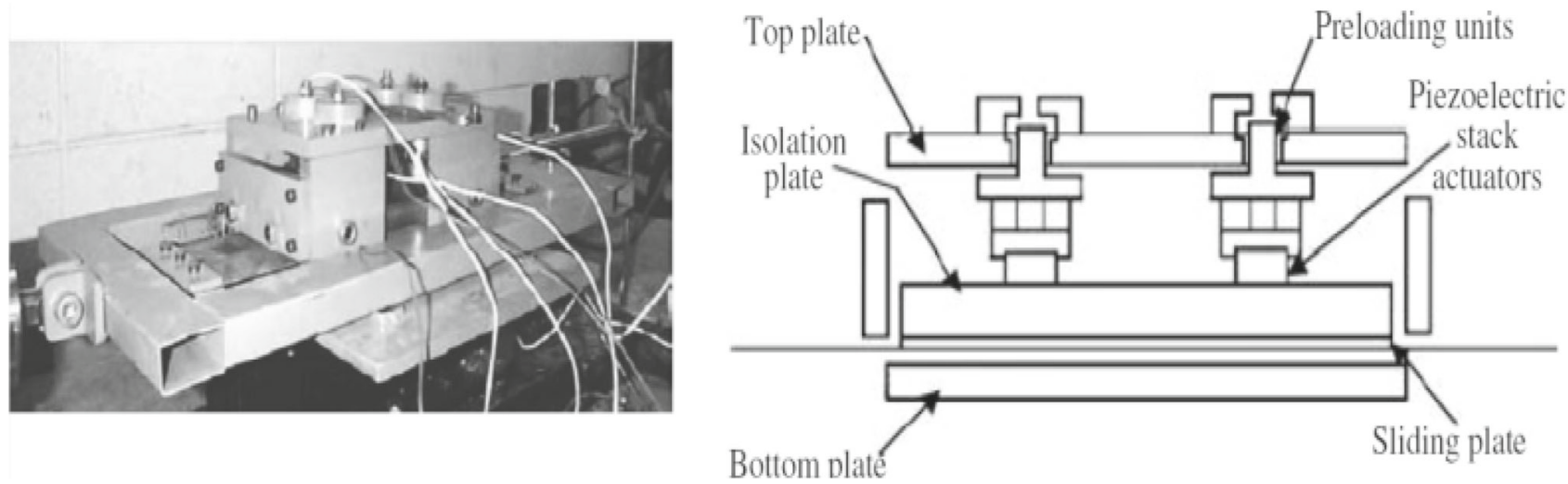

Fig. 7 Piezoelectric friction damper

our knowledge of its physical properties to maximize the efficiency of the damper is stated by the article $[85,86]$.

\subsection{Semi-active vibration absorbers}

Semi-active vibration absorber is also known as a semi-active hydraulic damper and also an Accumulated Semi-active Hydraulic Damper (ASHD). Figure 8 shows the accumulated semi-active hydraulic damper.

This device consists of a hydraulic jack, a valve and an accumulator. In these devices, the opening and the closing of the valve regulates the stiffness and decides the damping of the hydraulic damper. The energy dissipation is obtained to the optimal value by using a control algorithm that controls the oil flow in the hydraulic jack; in turn, controls the direction in which the device acts.

\subsection{Semi-active stiffness control devices}

Semi-active stiffness control device consists of many parts like solenoid valve, a tube which is connecting to the cylindrical chamber, a hydraulic cylinder with a double-acting piston rod as shown in Fig. 9. The structural stiffness reduces when the valve is open, has it unlocks the beam brace connection and increases the structural stiffness when the valve is closed, has fluid cannot flow so the beam will be locked to the brace as stated in the article [87]. Resetting semi-active stiffness damper has been studied and results show the effectiveness of this damper in reducing the structural control for the near field earthquake as stated in the article [88]. Resetting semiactive stiffness dampers was replaced by a novel mechanism to form resetting passive stiffness damper which is used for the base isolation of a nonlinear building subjected for near field earthquake in [89].

\subsection{Electro-rheological dampers}

The Electro-Rheological (ER) damper has a hydraulic cylinder that contains dielectric particles which are suspended in a viscous fluid which is free-flowing fluid. These dielectric particles when exposed to electric current they polarize and align themselves in a certain manner and resist the free-flowing liquid. This conversion from free-flowing to the resistive nature takes place within no time making the electro-rheological fluid exhibit the reversible nature which could be achieved only by fluctuating the electric power which in turn is regulated by a preset control algorithm to control the voltage of the power supply. Makris was the first to use the smart properties of the electro-rheological fluid to alter the damper force production. In this type of dampers, energy dissipation takes place by shearing of fluid and due to orifice of viscous fluid which creates a friction effect. Limitations of this type of dampers are the yield stress is limited and a very high voltage is required to regulate the ER fluid.

\subsection{Magneto-rheological dampers}

Magneto-Rheological (MR) damper works the same as electro-magnetic damper except that it works with the electrical field in the electromagnetic damper and magnetic field in the magneto-rheological damper. This MR fluid was discovered by Jacob Rabinow in the 1950s. The magnetorheological damper consists of cylindrical which consists of macro-sized magnetically polarizable particles suspended in a viscous fluid like silicon oil. When the magnetic field is applied, the magnetic particles are polarized and it shows the visco-plastic behavior which makes the fluid resistive. The resistive nature occurs from free-flowing fluid to a semi-solid state within some seconds which is possible by changing the effect of the magnetic field which is regulated by the control algorithm. The advantage of MR damper is yielding strength is more, it is stable in the wider range of temper- 
Fig. 8 Schematic view of the accumulated semi-active hydraulic damper

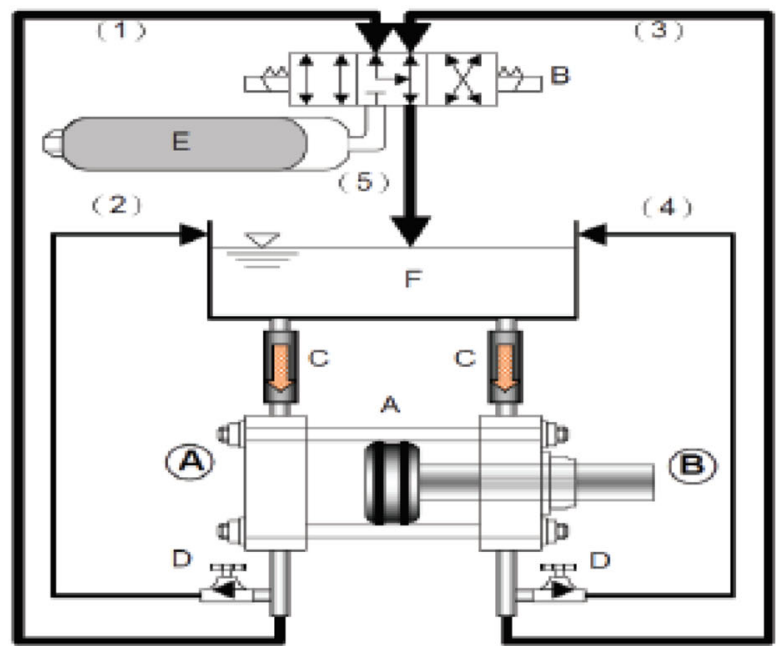

(1) Left primary circuit

(2) Left secondary circuit

(3) Right primary circuit

(4) Right secondary circuit

(5) To accumulator

\section{A. Hydraulic jack \\ B. Directional valve \\ C. Check valves \\ D. Relief valves \\ E. Accumulator \\ F. Oil box}

(A) Connect to structure

(B) Connect to bracing

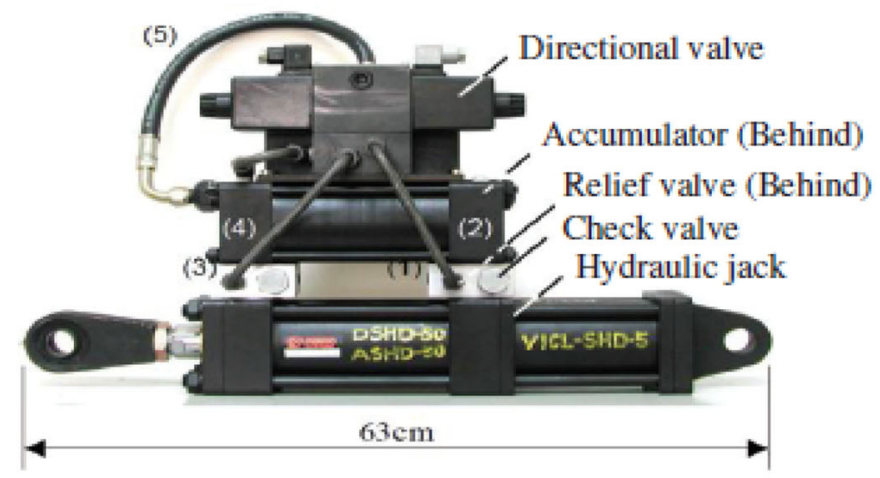

ature and less power is required to regulate the MR fluid. MR damper has been proven to be a promising device in structural control [90]. In the article [90], MR damper has been controlled by clipped optimal control which is acceleration feedback control to regulate damper, this combination of semi-active control has proven to be effective in controlling the vibration of the structure. Many studies have considered MR damper in controlling the structure with different control algorithms like adaptive control, genetic-based fuzzy logic control, bang-bang, clipped optimal control as presented in articles [91-93]. The authors in paper [91] compared the performance of the various controllers like fuzzy control method, simple adaptive control, passive-on and passive off method in structural control as shown in Fig. 10 displays the displacement of the each floor.

\subsection{Semi-active viscous fluid damper}

In this type of damper, the intensity of viscous fluid flow is controlled through closed solenoid value through the bypass loop. The value is adjusted by the already existing control algorithm which uses very little power to tune the damper behavior. When the valve opening is large the damper force production is less due to less flow resistance and when the valve is partially open the force produced is more due to large flow resistance. Energy is dissipated via the friction between the flow, the bypass loop, and orifices in the piston head. The viscous damper is used in much real application in structural control as stated in articles [94, 95].

\subsection{Variable orifice damper}

Using variable orifice valve in a conventional hydraulic fluid damper to control the flow of liquid which uses very little power to produce the damping force was first used by Feng and Shinozuka to control the motion of the bridges [96].

As the semi-active system can work with battery power it is the significant advantage of this system. This system can change the power output only with the little external power supply in a wide range which makes it work due to uncertainty like an earthquake, power cut, or some inability of the power transmission. This advantage has made the semi-active control system the topic of research in recent years. There is a small limitation with this system is that the requirement of 


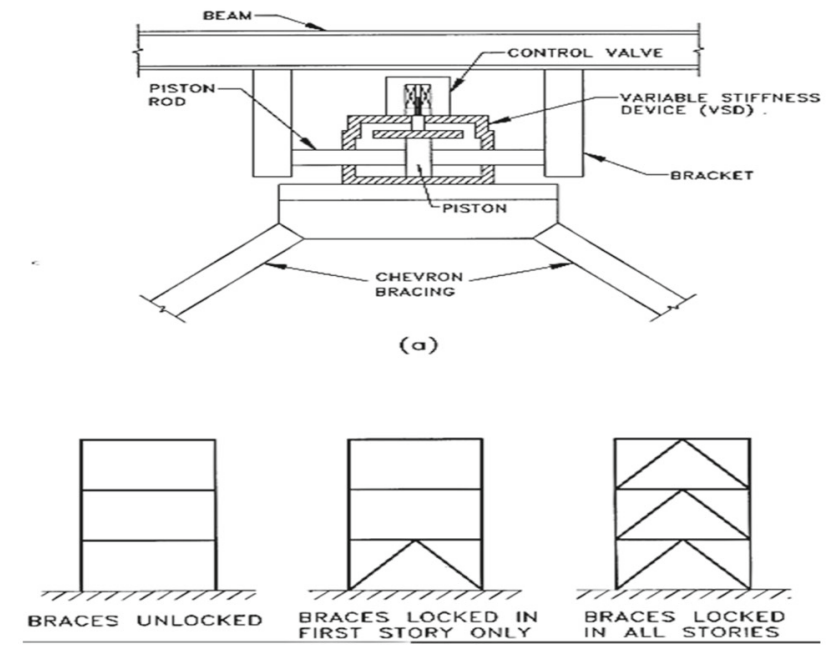

Fig. 9 Semi-active stiffness control devices

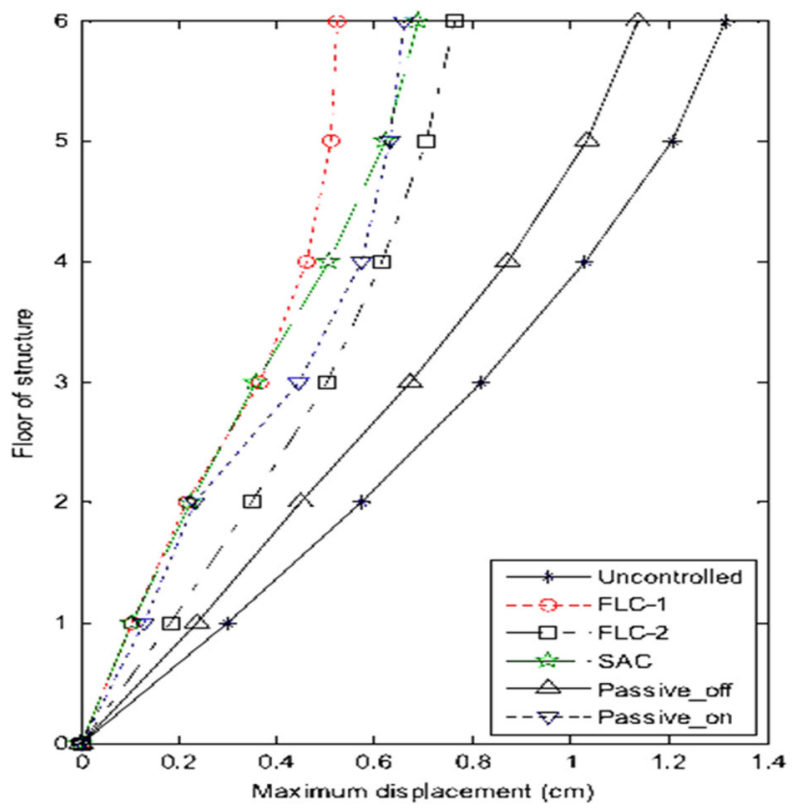

Fig. 10 Maximum displacement of each floor controlled by various controller

the computer-controlled feedback system and sensors needed for the measurements.

\section{Hybrid control}

Hybrid systems which are considered between passive and active control system, in terms of procedure they are the combined use of passive and active control system which utilize the external energy to control the structure. In semi-active control, the capacity of the active control cannot be utilized but in hybrid, both the passive and active control force which is a higher control force can be utilized. As it uses the active

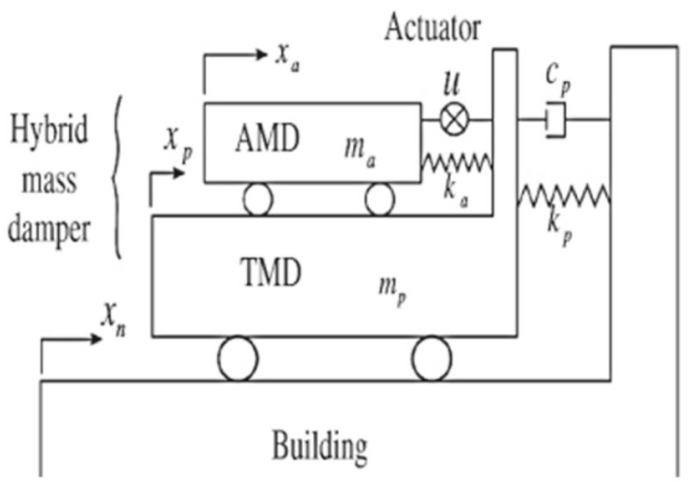

Fig. 11 Mechanical diagram of the hybrid mass damper

control strategy it uses a large amount of external power and cost involvement is more is considered to be a major concern [97]. The hybrid protective system consists of hybrid base isolation, hybrid mass dampers and hybrid damper-actuator bracing system [98].

\subsection{Hybrid mass dampers}

Hybrid Mass Damper (HMD) is the combination of an active actuator and TMD or it can be a combination of the TMD with AMD as presented in articles [99, 100]. Figure 11 shows the mechanical diagram of HMD.

In HMD the connection of AMD to TMD will make the reduction in the mass used for AMD to 10-15\%. The AMD with connection to TMD in HMD will perform only for the higher modes of the structure while the fundamental modes are taken care of by TMD is stated in the article [73]. This makes the HMD work with less energy consumption related to AMD with a similar output which makes it economical and will promote the widespread application for the structural control. But the main concern is the mass used in HMD requires large space [101]. An alteration to TMD was studying in articles [77, 102] with the combination of TLD, where TLD was rigidly attached to the secondary mass which is connected to the primary structure through the spring system, this combination was called as Hybrid Mass Liquid Damper (HMLD) as shown in the Fig. 12. HMLD works well when the secondary spring's flexibility is optimum and when the secondary spring is rigid it acts like the passive tuned mass directly attached to the structure, many studies have been conducted as elucidated in the article [103].

\subsection{Hybrid base-isolation systems}

The hybrid base isolation system consists of a base isolator and the controllable damper in the system to reduce the vibration of the structure [104, 105]. In the article [106] hybrid base-isolation systems are implemented to the structure by 


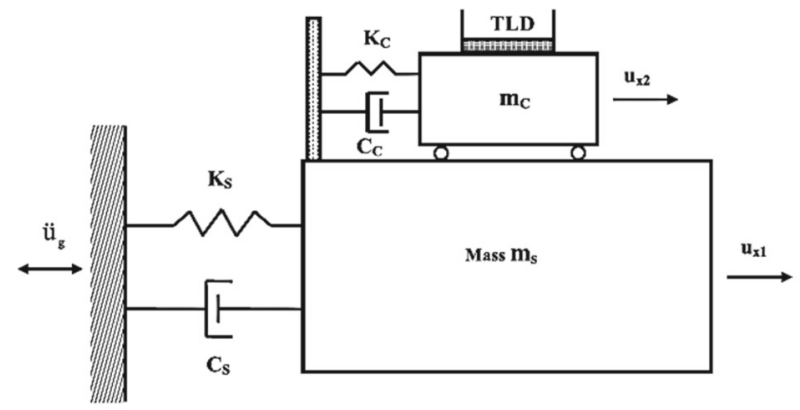

Fig. 12 Mechanical diagram of the hybrid mass liquid damper

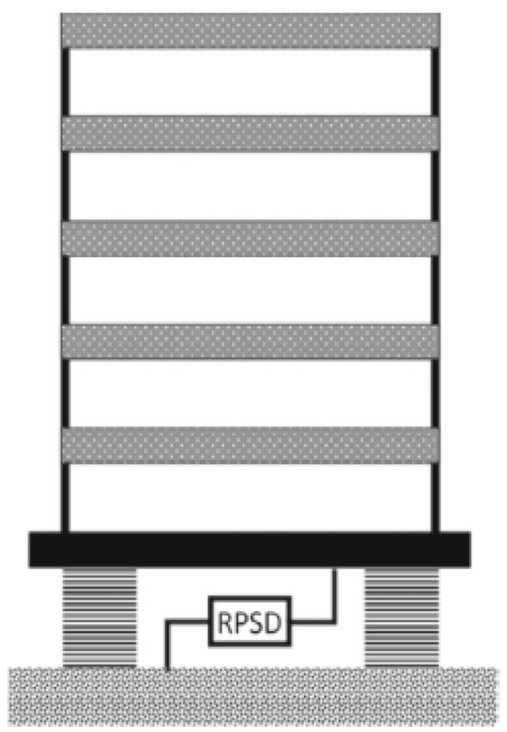

Fig. 13 Resetting passive stiffness damper in the isolation system

using the laminated rubber bearings as isolators and MR damper is attached between the ground and the base to control the system. In the other hybrid base isolation systems used in the article [107], isolators were used for the system between the foundation and the base and an active tendon system is used in the superstructure. A study was conducted in the article [89] to compare the effect of different passive dampers, semi-active dampers and a hybrid seismic protective system like a passive viscous fluid damper, passive friction damper, resetting semi-active stiffness damper and resetting passive stiffness damper as shown in Fig. 13.

\subsection{Hybrid damper-actuator bracing control}

Hybrid damper-actuator bracing control was introduced in the 1990s by Cheng and Jiang [108] by using K-bracing. As an active control part, hydraulic actuators are used and many passive control devices like mass, spring and viscous dampers are used. The main advantage of this system is its capacity to either combine the actuator and damper or to separate them. A Hybrid damper-actuator bracing system was introduced in the article [109], where the active controller and viscoelastic damper and hydraulic actuator are used as passive devices that are attached to the bracing confined to the structure floor.

The use of hybrid control has the advantage of both the active and passive control systems. Its main advantages are that it is compact, more efficient and mainly it is practicably implementable in the real system. But the limitation is the requirement of external power as it uses the active control system.

There is much recent development in the control strategy using different dampers. the recent development in the dampers are mega pall friction damper, buckling inhibited metal shear panel and crescent-shaped brace, compressionfree brace, prestressed lead extrusion damper, friction spring damper, triangular added damping and stiffness used all over the world [110]. japan has introduced some dampers in recent years like high capacity oil damper, inertia with acceleration mechanism, high capacity buckling restrained brace with triple-core plates, shear panel damper with a concave shape, hysteretic damper using stainless steel, hysteretic damper using $\mathrm{Fe}-\mathrm{Mn}-\mathrm{Si}$-based alloy, variable-friction-force slip damper, oil damper with visco-elastic material, friction damper with multistage friction force, friction damper using ring springs, semi-active oil damper with energy recovery system as presented in an article [110].

\section{Stochastic control}

Stochastic is jargon for randomness, thus the stochastic control of the tall building is randomness taken in any variable that has a chance of fluctuation at any instant of time. In the structural control system, the loads are of a significantly random nature which is irregular and cannot be predicted. In the literature uncertainty is considered as the random noise in feedback control, dynamic properties of the system, over-estimation of damping at the design stage, inherent randomness in the dynamical behavior of the dampers, desired random excitations passed through the suitable filters providing stochastic parameters of earthquake disturbances [111-113]. Thus in many studies the stochastic earthquake excitation is produced by taking the property of the soil in the site and connecting them to the seismic motion at the bedrock [114-116]. Paper [116] targeted to enhance the MR damper by controlling randomly seismic excited structures by adopting a bounded Hrovat algorithm. As earthquake the wind load is also taken as random excitation representing the Davenport spectrum by taking the cross power spectral density of along-wind force [117]. In this paper the stochastic control of wind excited structure is considered, which uses semi-active magneto-rheological tuned liquid column damper adopting statistical linearization method and the opti- 
mal linear quadratic control strategy. The authors of the paper [118] considered stationary Gaussian random process for fluctuating part of the wind vector using a power spectral density matrix, cogitated as a second-order linear filter and it is diagonalized in eigenvector space. In these literature uncertainty would be in the form of random noise in feedback control, dynamic properties of the system, over-estimation of damping at the design stage etc.

\section{Big data analysis}

Big data in the construction industry is complex heterogeneous data managements for the extraction of useful insights from data. Authors in paper [119] has given a brief review of big data utilization in the construction sector divided into big data engineering and big data analysis. Under big data engineering, authors have illustrated big data processing, storage, distributed file system, and databases. Big data analysis involves data mining, statistics, and machine learning that involves regression, classification, clustering, information retrieval, natural language processing $[119,120]$. There are new strategies proposed to overcome some limitations of big data complexity like auto-regression moving average modeling, probabilistic graphical model, system identification techniques, vector support machines, data mining, and clustering, etc. [121-123]. In the big data analysis for tall structures, there needs a novel proposal to reduce the complexity in the data process analysis and time consumption which serves as the efficient techniques in the construction sectors of tall buildings.

\section{Conclusion}

This paper has presented a general review of the evolution of the construction from the Paleolithic age to the most modern skyscrapers with the development from temporary to permanent construction with the introduction to reinforced material used in construction practice and the structural protective systems. This review also briefs about the structural control systems with their classification against the uncertainty and natural disasters like wind and earthquake. The paper has also reviewed the structural behavior against the wind and earthquake load. The structural control devices like passive controllers, its classification as base isolators and its further types, energy dissipaters and energy transfer devices are presented with a summary. The active control device like active mass damper, active bracing system and pulse generation system is elucidated. The limitations of the above system have discovered smart devices like the semi-active dampers and hybrid dampers. These innovative devices have proved to deliver better performance than the passive and active devices. The semi-active protective devices such as semiactive tuned mass damper, semi-active liquid damper, semiactive friction damper, semi-active stiffness control device, electro-rheological damper, magneto-rheological damper, semi-active viscous fluid damper, variable orifice damper are summarized. Under hybrid protective system hybrid mass damper, hybrid base isolation and hybrid damper actuator bracing system are systematically explained. All the control devices have their advantages and disadvantages which have been elaborated in the paper. Although designing structural control devices in the real-time application is upcoming practice and relatively new advancement in construction it has enormous uncapped potential in the construction sector. The brief review about stochastic vibration control, big data analysis on the tall structure and some comparative study of tall structural system behavior are illustrated. There is a need for further study on linear and non-linear analysis of the tall structure with the efficient performing dampers and actuators that need a comparison of the control system performances such as robust optimal control and stochastic optimal control in regulating the tall structure.

\section{Future scope}

The structural control systems review is discussed in this paper. There is a need for a state-of-art review on different structural forms and the implementation of the new control algorithms to enhance the performance of the structure in mitigating vibration. Outrigger being one of the tall structural forms, in which the damped outrigger is a new concept of the decade. This is a new area of research that can be analyzed with the better control algorithm with the suitable dampers and actuators for the outrigger structural control. The adaptive control, stochastic optimal control and robust control techniques can be incorporated for the control of the damped outrigger structure and other structural forms with the big data techniques involved in the performance improvement of the tall building vibration control techniques.

Acknowledgements We would like to thank the Manipal Academy of Higher Education for all the support provided.

Funding Open access funding provided by Manipal Academy of Higher Education, Manipal.

Open Access This article is licensed under a Creative Commons Attribution 4.0 International License, which permits use, sharing, adaptation, distribution and reproduction in any medium or format, as long as you give appropriate credit to the original author(s) and the source, provide a link to the Creative Commons licence, and indicate if changes were made. The images or other third party material in this article are included in the article's Creative Commons licence, unless indicated otherwise in a credit line to the material. If material is not included in the article's Creative Commons licence and your intended use is not permitted by statutory regulation or exceeds the 
permitted use, you will need to obtain permission directly from the copyright holder. To view a copy of this licence, visit http://creativecomm ons.org/licenses/by/4.0/.

\section{References}

1. Niroumand H, Zain MFM, Jamil M, Niroumand S (2013) Earth architecture from ancient until today. In: Proceedings of social and behavioral sciences, pp 222-225

2. Smith B, Coull A (1991) Tall building structures: analysis and design. Wiley, New York

3. Taranath BS (1998) Steel concrete and composite design of tall buildings. McGraw-Hill, New York

4. Taranath BS (2010) Reinforced concrete design of tall buildings. CRC Press, Boca Raton

5. Chopra AK (2001) Dynamics of structures - theory and applications to earthquake engineering. Prentice-Hall, New Jersey

6. Kodmany KA (2015) Tall buildings and elevators: a review of recent technological advances. Buildings 5:1070-1104

7. Sharma A, Mittal H, Gairola A (2018) Mitigation of wind load on tall buildings through aerodynamic modifications: review. J Build Eng 18:180-194

8. Wood A (2015) 100 of the world's tallest building. Council of Tall Building and Urban Habitat

9. Balestrino A, Landi A (1993) Vibrational control: from theory to practice. In: 12th Triennial World Congress

10. Meerkov S (1980) Principle of vibrational control: theory and applications. IEEE Trans Autom Control 25(4):755-762

11. Aly AM, Abburu S (2015) On the design of high-rise buildings for multihazard: fundamental differences between wind and earthquake demand. Shock Vib 148681

12. Longarini N, Cabras L, Zucca M, Chapain S, Aly AM (2017) Structural improvements for tall buildings under wind loads: comparative study. Shock Vib 2031248

13. Spence SMJ, Kareem A (2014) Tall buildings and damping: a concept-based data-driven model. J Struct Eng 140(5):e.04014005

14. Smith R, Willford M (2008) Damping in tall buildings-uncertainties and solutions. In: Proceedings of of 17th IABSE Congress Chicago, Chicago

15. Pnevmatikos N (2017) Pole placement algorithm for control of civil structures subjected to earthquake excitation. J Appl Comput Mech 3(1):25-36

16. Housner GW, Bergman LA, Caughey TK, Chassiakos AG, Claus RO, Masri SF, Skelton RE, Soong TT, Spencer BF Jr, Yao TP (1997) Structural control: past, present, and future. J Eng Mech 123(9):897-971

17. Cesar MB, de-Barros RC (2013) Passive control of civil engineering structures. In: Proceedings of 4th international conference on integrity, reliability, and failure of mechanical systems, pp 23-27

18. Takewaki I, Fujita K, Yamamoto K, Takabatake H (2011) Smart passive damper control for greater building earthquake resilience in sustainable cities. Sustain Cities Soc 1(1):3-15

19. Nie S, Zhuang Y, Wang Y, Guo K (2018) Velocity \& displacementdependent damper: a novel passive shock absorber inspired by the semi-active control. Mech Syst Signal Process 99:730-746

20. Anwar N (2016) Smart systems for smart structures. Technology, December

21. Naeim F, Kelly JM (1999) Design of seismic isolated structures-theory to practice. Wiley, New York

22. Hayashikawa T, Julian FDR (2014) Effect of hardening of leadrubber bearings on nonlinear behavior of highway viaducts under great Earthquakes. In: Proceedings of 13th world conference on earthquake engineering vancouver, Canada
23. Qamaruddin M (1978) Development of brick building systems for improved earthquake performance. Ph. D. Dissertation, University of Roorkee, Roorkee, India

24. Kelly JM, Beucke KE (1983) A friction damped base isolation system with failsafe characteristics. Earthq Eng Struct Dyn 11:33-56

25. Jangid RS, Londhe YB (1998) Effectiveness of elliptical rolling rods for base isolation. J Struct Eng 124(4):469-472

26. Mokha A, Constantinou M, Reinhorn A (1990) Teflon bearings in base isolation I: testing. J Struct Eng 116(2):438-454

27. Arya AS (1984) Sliding concept for mitigation of earthquake disaster to masonry buildings. In: Proceedings of 8th world conference on earthquake engineering, vol 5, pp 951-958

28. Li L (1984) Base isolation measure for a seismic buildings in China. In: Proceedings of eighth world conference on earthquake engineering, vol 4, pp 791-798

29. Ontiveros-Pereza SP, Miguela LFF, Riera JD (2019) Reliabilitybased optimum design of passive friction dampers in buildings in seismic regions. Eng Struct 190:276-284

30. Ontiveros-Perez SP, Miguel LFF, Fadel LF (2017) Robust simultaneous optimization of friction damper for the passive vibration control in a colombian building. Proc Eng 199:1743-1748

31. Zayas VA, Low SS, Mahin SA (1990) A simple pendulum technique for achieving seismic isolation. Earthq Spect 6(2):317-333

32. Fenz DM, Constantinou MC (2006) Behaviour of the double concave friction pendulum bearing. Earthq Eng Struct Dyn 35(11):1403-1424

33. Fenz DM, Constantinou MC (2008) Modeling triple friction pendulum bearings for response-history analysis. Earthq Spect 24(4):1011-1028

34. Pranesh M, Sinha R (2000) VFPI: an isolation device for a seismic design. Earthq Eng Struct Dyn 29(5):603-627

35. Tsai CS, Chiang TC, Chen BJ (2003) Finite element formulations and theoretical study for variable curvature friction pendulum system. Eng Struct 25(14):1719-1730

36. Lu LY, Shih MH, Wu CY (2004) Near-fault seismic isolation using sliding bearings with variable curvatures. In: Proceedings of 13th world conference on earthquake engineering

37. Lu LY, Wang J, Hsu CC (2006) Sliding isolation using variable frequency bearings for near-fault ground motions. In: Proceedings of 4 th international conference on earthquake engineering, Taipei, Taiwan

38. Panchal VR, Jangid RS (2008) Seismic isolation of bridge using variable curvature friction pendulum system. In: Proceedings of 14th world conference on earthquake engineering, pp 12-17

39. Krishnamoorthy A (2010) Seismic isolation of bridges using variable frequency and variable friction pendulum isolator system. Struct Eng Int 20(2):178-184

40. Krishnamoorthy A (2011) Variable curvature pendulum isolator and viscous fluid damper for seismic isolation of structures. J Vib Control 17(12):779-1790

41. Krishnamoorthy A (2015) Seismic control of continuous bridges using variable radius friction pendulum systems and viscous fluid dampers. Int J Acoust Vib 20(1):24-35

42. Soong TT, Spencer BF Jr (2002) Supplemental energy dissipation: state-of-the-art and state-of-the-practice. Eng Struct 24:243-259

43. Constantinou MC, Soong TT, Dargush GF (1998) Passive energy dissipation systems for structural design and retrofit. MCEER Monograph No. 1, Multidisciplinary Center for Earthquake Engineering Research, State University of New York at Buffalo

44. Hracov S, Naprstek J (2017) Approximate complex Eigen solution of proportionally damped linear systems supplemented with a passive damper. Proc Eng 199:1677-1682

45. Javidialesaadi A, Wierschem NE (2019) Energy transfer and passive control of single-degree-of-freedom structures using a one-directional rotational inertia viscous damper. Eng Struct 196:1-12 
46. Silvestri S, Trombetti T (2007) Physical and numerical approaches for the optimal insertion of seismic viscous dampers in shear-type structures. J Earthq Eng 11(5):787-828

47. Silvestri S, Gasparini G, Trombetti T (2011) Seismic design of a precast R.C. structure equipped with viscous dampers. Earthq Struct 2(3):297-321

48. Whittle JK, Williams MS, Karavasilis TL, Blakeborough A (2012) A comparison of viscous damper placement methods for improving seismic building design. J Earthq Eng 16:540-560

49. Aydin E, Ozturk B, Dutkiewicz M (2019) Analysis of the efficiency of passive dampers in multi-storey buildings. J Sound Vib 439:17-28

50. Mehrabi MH, Suhatril M, Ibrahim Z, Ghodsi SS, Khatibi H (2017) Modeling of a viscoelastic damper and its application in structural control. PLoS ONE 12(6):e.0176480

51. Aghlara R, Tahir MM (2018) A passive metallic damper with replaceable steel bar components for earthquake protection of structures. Eng Struct 159:185-197

52. Aghlara R, Tahir MM, Adnan AB (2018) Experimental study of pipe-fuse damper for passive energy dissipation in structures. $\mathrm{J}$ Constr Steel Res 148:351-360

53. Frahm H (1911) Device for damping vibration of bodies. U.S. Patent 989-958, April 18

54. Xu Y, Zhang W (2001) Closed-form solution for seismic response of adjacent buildings. Earthq Eng Struct Dyn 31(2):235-259

55. Hartog JPD (1940) Mechanical vibration, 2nd edn. Mc-Graw Hill, New York

56. Akyurek O, Suksawang N, Go TH, Tekeli H (2019) Performance evaluation of a reinforced concrete building strengthened respectively by the infill wall, active and passive tuned mass damper under seismic load. Comput Struct 223:e 106097

57. Chang CM, Shia S, Lai YA (2018) Seismic design of passive tuned mass damper parameters using active control algorithm. J Sound Vib 426:150-165

58. Elias S, Matsagar V (2017) Research developments in vibration control of structures using passive tuned mass dampers. Annu Rev Control 44:129-156

59. Shi W, Wang L, Lu Z, Wang H (2019) Experimental and numerical study on adaptive-passive variable mass tuned mass damper. J Sound Vib 452:97-111

60. Wang L, Shi W, Zhang Q, Zhou Y (2019) Study on adaptivepassive multiple tuned mass damper with variable mass for a largespan floor structure, Engineering Structures, in press

61. Marko J (2006) Influence of damping systems on building structures subject to seismic effects. Ph.D. Dissertation, Queensland University of Technology, Australia

62. Rohman MA, Leipholz HH (1983) Active control of tall buildings. J Struct Eng 109(3):628-645

63. Pastia C, Luca S G, Chira F, Rosca VO (2005) Structural control systems implemented in civil engineering. Bulletin of the Polytechnic Institute of Jassy

64. Shooshtari M, Saatcioglu M (2004) Active structural control of concrete structures for earthquake effects. In: Proceedings of 13th World Conference on Earthquake Engineering

65. Kobori T, Takahashi M, Nasu T, Niwa N, Ogasawara K (1993) Seismic response controlled structure with active variable stiffness system. Earthq Eng Struct Dyn 22:925-941

66. Loh C, Ma M (1994) Active-damping or active-stiffness control for seismic excited buildings. In: Proceedings of the first world conference on structural control, Los Angeles: International Association for Structural Control

67. Yamada K, Kobori T (1995) Control algorithm for estimating future responses of active variable stiffness structure. Earthq Eng Struct Dyn 24:1085-1099

68. Yang JN, Wu JC, Li Z (1996) Control of seismic excited buildings using active variable stiffness systems. Eng Struct 18(8):589-596
69. Pnevmatikos N, Gantes CJ (2009) Design and control algorithm for structures equipped with active variable stiffness devices. Struct Control Health Monit 17(6):591-708

70. Datta TK (2003) A state-of-the-art review on active control of structures. ISET J Earthq Technol 40(1):1-17

71. Saaed TE, Nikolakopoulos G, Jonasson JE, Hedlund H (2013) A state-of-the-art review of structural control systems. J Vibration Control 21(5):919-937

72. Bitaraf M, Hurlebaus S (2013) Semi-active adaptive control of seismically excited 20-story nonlinear building. Eng Struct $56: 2107-2118$

73. Saaed TE (2015) Structural control and identification of civil engineering structures. Ph.D. Dissertation, Lulea University of Technology, Sweden, March

74. Nagarajaiah S (1997) Semi-active control of structures. Proceedings of Structures Congress XV. ASCE, Portland, pp 1574-1578

75. Rezaee M, Aly AM (2019) Proposed theory of semi active gains for smart dampers in MDOF systems. J Struct Eng 145(12):04019155

76. Owji HR, Shirazi AHN, Sarvestani HH (2011) A comparison between a new semi-active tuned mass damper and an active tuned mass damper. Proc Eng 14:2779-2787

77. Demetris D, Nikolaos N (2017) Hybrid semi-active mass dampers in structures; assessing and optimising their damping capacity. Proc Eng 199:3103-3108

78. Maslanka M (2019) Optimised semi-active tuned mass damper with acceleration and relative motion feedbacks. Mech Syst Signal Process 130:707-731

79. Altay O, Nolteernsting F, Stemmler S, Abel D, Klinkel S (2017) Investigations on the performance of a novel semi-active tuned liquid column damper. Proc Eng 199:1580-1585

80. Cheng FY, Jiang H, Lou K (2008) Smart structures: innovative systems for seismic response control. CRC Press, Boca Raton

81. Wu YG, Li L, Fan Y, Ma HY, Wang WJ, Christen JL, Ichchou M (2019) Design of semi-active dry friction dampers for steady-state vibration: sensitivity analysis and experimental studies. J Sound Vib 459:1-22

82. Chen C, Chen G (2004) Shake table tests of a quarter-scale threestorey building model with piezoelectric friction dampers. Struct Control Health Monit 11:239-257

83. Ng CL, Xu YL (2007) Semi-active control of a building complex with variable friction dampers. Eng Struct 29:1209-1225

84. Xu YL, Chen B (2008) Integrated vibration control and health monitoring of building structures using semi-active friction dampers: part I-methodology. Eng Struct 30:1789-1801

85. Santos MBD, Coelho HT, Neto FPL, Mahfoud J (2017) Assessment of semi-active friction dampers. Mech Syst Signal Process 94:33-56

86. Santos MBD, Coelho HT (2019) Assessment of semi-active friction dampers in auxiliary mass dampers suspension. Eng Struct 186:356-368

87. Nemir DC, Lin Y, Osegueda RA (1994) Semi-active motion control using variable stiffness. J Struct Eng 120(4):1291-1306

88. Yang JN, Kim JH, Agrawal AK (2000) Resetting semi-active stiffness damper for seismic response control. J Struct Eng 126(12):1427-1433

89. Walsh KK, Sallar G, Steinberg EP (2019) Hybrid base-isolation of a nonlinear building using a passive resettable stiffness damper. Eng Struct 178:206-211

90. Dyke SJ, Spencer BF Jr, Sain MK, Carlson JD (1996) Modeling and control of magneto-rheological dampers for seismic response reduction. Smart Mater Struct 5(5):565-575

91. Bitaraf M, Ozbulut OE, Hurlebaus S, Barroso L (2010) Application of semi-active control strategies for seismic protection of buildings with MR dampers. Eng Struct 32:3040-3047 
92. Luu M, Rodrigo MDM, Zabel V, Konke C (2014) Semi-active magneto rheological dampers for reducing response of high-speed railway bridges. Control Eng Pract 32:147-160

93. Weber F (2014) Semi-active vibration absorber based on real-time controlled MR damper. Mech Syst Signal Process 46:272-288

94. Smith RJ, Wilford MR (2007) The damped outrigger concept for tall buildings. Struct Des Tall Special Build 16:501-517

95. Smith R (2016) The damped outrigger-design and implementation. Int J High-Rise Build 5:63-70

96. Spencer BF Jr, Nagarajaiah S (2003) State of the art of structural control. J Struct Eng pp 845-856

97. Connor JJ, Klink BSA (1996) Introduction to motion based design. Computational Mechanics Publications, Boston

98. Cheng FY, Jiang H, Lou K (2008) Smart structures-innovative systems for seismic response control, New York, CRC press Taylor \& Francis Group

99. Fujita T (1994) Development of hybrid mass damper with convertible active and passive modes using AC-servomotor for vibration control of tall buildings. In: Proceedings of the first world conference on structural control, Los Angeles: International Association for Structural Control

100. Chesne S, Inquiete G, Cranga P, Legrand F, Petitjean B (2019) Innovative hybrid mass damper for dual-loop controller. Mech Syst Signal Process 115:514-523

101. Cheng FY, Jiang H, Lou K (2010) Smart structures: innovative systems for seismic response control. CRC Press, Boca Raton

102. Banerji P, Samanta A (2011) Earthquake vibration control of structures using hybrid mass liquid damper. Eng Struct 33:1291-1301

103. Love JS, Tait MJ, Nezhad HT (2011) A hybrid structural control system using a tuned liquid damper to reduce the wind induced motion of a base isolated structure. Eng Struct 33:738-746

104. Saaed TE, Nikolakopoulos G, Jonasson JE, Hedlund H (2015) A state-of-the-art review of structural control systems. J Vib Control 21(5):19-937

105. Yang JD (1991) A seismic hybrid control systems for building structures. ASCE J Eng Mech

106. Yoshioka H, Ramallo JC, Spencer BF Jr (2002) Smart base isolation strategies employing magneto-rheological dampers. J Eng Mech 128(5):540-551

107. Cheng FY, Jiang H (1998) Optimum control of a hybrid system for seismic excitations with state observer technique. Smart Mater Struct 7(5):654

108. Cheng FY, Jiang H (1998) Optimum control of a hybrid system for seismic excitations with state observer techniques. Smart Mater Struct 7
109. Zhang XZ, Cheng FY, Jiang HP (2006) Hybrid actuator-damperbracing control (HDABC) system with intelligent strategy and soil-structure interaction. Eng Struct 28:2010-2022

110. Ikeda Y, Yamamoto M, Furuhashi T, Kurino H (2019) Recent research and development of structural control in Japan. Jpn Architect Rev 2(3):219-225

111. Sun J-Q, Luo ACJ (2012) Global analysis of nonlinear dynamics-stochastic control. Springer, Berlin, pp 253-276

112. Zhang W, Xu H, Wang H, Lin Z (2017) Stochastic systems and control: theory and applications. Math Probl Eng 4063015

113. Amini F, Vahdani R (2007) Modern control design of seismically excited tall buildings with uncertain dynamic characteristics. Int J Civ Eng 5(3):198-209

114. Peng YB, Yang JG, Li J (2015) Stochastic optimal control of MR damped structures with uncertain parameters. In: International conference on applications of statistics and probability in civil engineering, vancouver, Canada: July 12-15

115. Peng Y, Yang J, Li J (2016) Seismic risk-based stochastic optimal control of structures using magneto-rheological dampers. Nat Hazards Rev 18(1):B4016001-B4016013

116. Dowrick DJ (2009) Earthquake resistant design and risk reduction. Wiley, New York

117. Ni YQ, Ying ZG, Wang JY, Ko JM, Spencer BF Jr (2004) Stochastic optimal control of wind-excited tall buildings using semi-active MR-TLCDs. Prob Eng Mech 19:269-277

118. Zhu WQ, Luo M, Ying ZG (2004) Nonlinear stochastic optimal control of tall buildings under wind loading. Eng Struct 26:1561-1572

119. Bilal M, Oyedele LO, Qadir J, Munir K, Ajayi SO, Akinade OO, Owolabi HA, Alaka HA, Pasha M (2016) Big data in the construction industry: a review of present status, opportunities, and future trends. Adv Eng Inform 30:500-521

120. Cai G, Sankaran M (2016) Big data analytics in online structural health monitoring. Int J Prognos Health Manag 7(24):1-12

121. Entezami A, Sarmadi H, Behkamal B, Mariani S (2020) Big data analytics and structural health monitoring: a statistical pattern recognition-based approach. Sensors 20(8):2328

122. Cremona C, Santos J (2018) Structural health monitoring as a big-data problem. Struct Eng Int 28(3):243-254

123. Daissaoui A, Boulmakoul A, Karim L, Lbath A (2020) IoT and big data analytics for smart buildings: a survey. Proc Comput Sci 170:161-168 